\title{
Rietveld and Impedance Analysis of Cold and Hot Rolled Duplex and Lean Duplex Steels for Application in Paper and Pulp Industry
}

\author{
Luiza Esteves ${ }^{a *}$, Paulo Renato Perdigão Paiva ${ }^{b}$, Adolfo Kalergis do Nascimento Viana ${ }^{c}$, Vanessa de \\ Freitas Cunha Lins ${ }^{a}$ \\ ${ }^{a}$ Chemical Engineering Department, Federal University of Minas Gerais - UFMG, Avenida Antonio \\ Carlos, 6627, Belo Horizonte, $M G$, Brazil \\ ${ }^{b}$ Federal Center of Technological Education of Minas Gerais - CEFET, Av. Amazonas, 5855, Belo \\ Horizonte, $M G$, Brazil \\ ${ }^{c}$ APERAM South America, Praça $1^{\circ}$ de Maio, 9, Centro, Timóteo, MG, Brazil
}

Received: March 20, 2016; Revised: September 26, 2016; Accepted: October 20, 2016

\begin{abstract}
In this study, X-Ray Diffraction (XRD) and Rietveld Refinement were performed to identify and quantify the ferrite and austenite phase of cold and hot rolled duplex stainless steels (UNS S31803) and lean duplex stainless steels (UNS S32304). Electrochemical impedance spectroscopy (EIS) was applied to evaluate the chemical behavior of duplex and lean duplex stainless steels in white, green, and black liquors of paper and pulp industry. Rietveld analysis results showed a higher austenite content than the standard limit for duplex steels in the hot rolled condition. The hot rolling condition plays a major role in improving corrosion resistance in white liquor mainly for the lean duplex steel.
\end{abstract}

Keywords: Duplex stainless steels, Rietveld Refinement, Electrochemical impedance spectroscopy, Pulp and paper industry

\section{Introduction}

Duplex stainless steels (DSSs) presents a mixed microstructure of about equal proportions of $\gamma$-austenite (face-centered cubic, FCC) and $\alpha$-ferrite (body-centered cubic, BCC) ${ }^{1}$, and have existed for more than 70 years. DSSs can be readily hot rolled or cold-rolled. The microstructure depends on the chemical composition of the alloy and thermomechanical treatment ${ }^{2}$. The alloy elements can act as ferrite stabilizers (chromium, silicon, molybdenum, titanium and niobium) or austenite stabilizers (nickel, carbon, copper, nitrogen and manganese) ${ }^{3}$. Hence, the chemical composition of austenite and ferrite are different, resulting in different corrosion resistance in a given environment ${ }^{4}$. Phase fractions, and phase chemical compositions associated to the pitting resistance equivalent number $(\mathrm{PREN}=\text { wt. } \% \mathrm{Cr}+3.3 \text { wt. } \% \mathrm{Mo}+16 \mathrm{wt} . \% \mathrm{~N})^{4}$ of DSSs are affected significantly by solution-treatment parameters (temperature and time) $)^{4,5}$. Tan et al. ${ }^{4}$ reported that the pitting corrosion resistance of a super duplex stainless steel was determined by the pitting resistance equivalent number of weaker phase. On the other hand, improper heat treatment temperature can result in deleterious secondary phases $^{4}$. Also, plastic deformation may induce austenite to martensite transformation ${ }^{6,7}$.

The optimal phase balance in order to improve mechanical properties and corrosion resistance can be a range between $45 \%$ and $60 \%$ austenite. The microstructure is obtained by simultaneous control of the chemical composition and thermomechanical history (manufacturing process) ) $^{8,9}$.

The Rietveld method together with conventional X-ray diffraction (XRD) techniques was used to quantify the microstructural formation such as austenite; ferrite and sigma-phase in the cast super duplex steel after having been submitted to a series of heat-treated weldments ${ }^{10}$. The Rietveld method is a technique for refinement of crystal structures that uses data from X-ray or neutron diffraction ${ }^{11}$. This method is based on a mathematical fit for a real standard (experimental data) with a calculated standard (theoretical model) by minimizing the difference between measured and calculated points, through the method of least squares. The calculated standard is obtained from crystallographic databases such as Inorganic Crystal Structure Database (ICSD), Linus Pauling File (LPF), NIST Atomic Spectra Database, and Cambridge Structural Database (CSD). These databases provide the symmetry of the space group, atomic positions, occupation positions, and network parameters. To implement the method, XRD data are used exactly as obtained using the diffractometer, without any treatment ${ }^{11,12}$.

A major advantage of this method of quantification is that it uses all the points of an XRD spectrum and considers overlapping peaks, which usually make other methods of XRD quantification unfeasible. The parameters related to the diffractogram scanned data, which vary and are calculated during refinement, are as follows: scale factor, baseline

* e-mail: luizaeq@yahoo.com.br 
(background), peak profile, cell parameters, structure factor, displacement and preferred orientation ${ }^{11}$.

In the pulp and paper industry, carbon steel pulp mill equipment such as digesters and storage vessels have shown general corrosion and stress corrosion cracking. The duplex stainless steels have a higher corrosion and stress corrosion cracking resistance in high $\mathrm{pH}$ environments at severe conditions of pressure and temperature in relation to carbon steel and austenitic stainless steel. Therefore digesters and storage vessels are being replaced by duplex stainless steels ${ }^{13}$. The lean duplex steel is a cheaper alternative to duplex steels due to the lower contents of nickel and molybdenum ${ }^{14}$.

The Kraft process used in the paper and pulp industry is divided basically in three steps: firstly, the decomposition of the wood is performed by using active cooking chemicals (white liquor) constituted by sodium hydroxide and sodium sulfide $^{15}$. Secondly, the black liquors consisting of residual inorganic chemicals such as sodium sulfide, sulfate, sodium thiosulfate, sodium carbonate, and sodium hydroxide, and organic extractives in wood are formed due to the fragmentation reactions of lignin ${ }^{16}$. Lastly, there is a chemical recovery by combustion of strong black liquor which converts the recovered inorganic chemicals in melting which is dissolved in water, and the green liquor (sodium carbonate $\left(\mathrm{Na}_{2} \mathrm{CO}_{3}\right)$ and sodium sulfide $\left.\left(\mathrm{Na}_{2} \mathrm{~S}\right)\right)^{17}$ are produced. Furthermore the white liquor is considered to be the most aggressive of pulping liquors ${ }^{18}$.

The application of the Rietveld method of quantitative analysis for UNS 31803 and UNS 32304 is not found in literature. This study has also investigated the influence of microstructure of cold and hot rolled duplex steels on electrochemical properties of duplex and lean duplex steels in white, green, and black liquors from Pine and southern hardwood mix of an American pulp and paper industry.

\section{Materials and Methods}

\subsection{Material and Sample Preparation}

The duplex stainless steels, designated by Unified Numbering System (UNS) are UNS S31803 and UNS S32304 (lean Duplex), were supplied by APERAM South America (Brazil) in hot-rolled and cold-rolled conditions. The steels were examined as-received: hot rolled coils, annealed at $1075 \pm 25^{\circ} \mathrm{C}$ with $4 \mathrm{~mm}$ of thickness and cold rolled coils, annealed at $1070 \pm 25^{\circ} \mathrm{C}$, with a thickness of $1.8 \mathrm{~mm}$. The steel sheets were cut in dimensions of $1 \mathrm{~cm} \times 1 \mathrm{~cm}$ and the lengths were maintained parallel to the rolling direction. The chemical composition of these DSSs used in this work is shown in Table 1.

\subsection{Metallographic Analysis}

The samples were immersed in a modified Behara reagent, which consists of $80 \mathrm{~mL}$ distilled and deionized water, $20 \mathrm{~mL}$ of hydrochloric acid $(\mathrm{HCl})$, and $1 \mathrm{~g}$ potassium metabisulphite $\left(\mathrm{K}_{2} \mathrm{~S}_{2} \mathrm{O}_{5}\right) ; 2 \mathrm{~g}$ of ammonium difluoride $\left(\mathrm{NH}_{4} \mathrm{H}\right.$ $\mathrm{HF}$ ) was added to this stock solution just before the etching ${ }^{19}$. The microstructure analyses were carried out using a Leitz Metalloplan optical microscope (OM).

\subsection{X-Ray Diffraction (XRD)}

XRD analyses were performed to identify the phases present in the samples, using a Shimadzu 7000 equipment under the following operating conditions: $\mathrm{CuK} \alpha$ radiation $(35 \mathrm{KV} / 40 \mathrm{~mA})$, goniometer speed of $0.02^{\circ}$ per step $2 \theta$, with counting time of 5 seconds per step and collected from $30^{\circ}$ to $100^{\circ} 2 \theta$. Spectra interpretation was carried out by comparing standards contained in the database (PDF 02 International Centre for Diffraction Data, ICDD, 2003).

The Rietveld refinement was performed using the GSAS and interface EXPGUI program ${ }^{20}$. The Thompson-Cox-Hastings pseudo-Voigt profile function was used, and the background was adjusted by Chebyschev polynomial. Scale factor, unit cell, background radiation, profile asymmetry, the full width at half height from the instrumental broadening parameters obtained with a standard, atomic position, isotropic atomic displacements and cations occupational factors were refined. The values for $\mathrm{R}_{\mathrm{p}}$ (profile factor), $\mathrm{R}_{\mathrm{Bragg}}$ (Bragg's index), $\mathrm{R}_{\mathrm{wp}}$ (weighed profile factor), $\chi^{2}$ and the graphs obtained at every 3 cycles of refinement were measured to check quality of refinement and to better monitoring the results.

\subsection{Electrochemical Analysis}

Electrochemical impedance spectroscopy (EIS) was performed using a Gamry potentiostat. A three-electrode electrochemical cell was used with a saturated calomel electrode (SCE) as the reference with Luggin capillary and platinum (Pt) wire as a counter electrode, and the duplex stainless steel as the working electrode. The open circuit potential measurements were performed for $1 \mathrm{~h}$ or until to obtain a stable open circuit potential value. The amplitude sine-wave of the applied potential is $10 \mathrm{mV}$ from $100 \mathrm{kHz}$ to $5 \mathrm{mHz}$ with 7 points per decade. The measurements were performed in triplicate to ensure the reproducibility.

Table 1: Chemical composition of the DSSs investigated (wt $\%$ ).

\begin{tabular}{lcccccccccc}
\hline Steel & Rolling & Cr & Ni & Mo & N & C & Si & Mn & S \\
\hline 31803 & Cold & 22.43 & 5.34 & 2.67 & 0.11 & 0.012 & 0.29 & 1.85 & 0.0004 \\
31803 & Hot & 22.45 & 5.31 & 2.63 & 0.11 & 0.013 & 0.38 & 1.81 & 0.0005 \\
32304 & Cold & 22.40 & 4.10 & 0.29 & 0.14 & 0.015 & 0.46 & 1.55 & 0.0002 \\
32304 & Hot & 22.87 & 4.20 & 0.27 & 0.15 & 0.011 & 0.20 & 1.45 & 0.0004 \\
\hline
\end{tabular}


The experimental impedance spectra were fitted using Z-Viewsoftware version 3.4d. The electrochemical tests were performed in white, green and black liquors, supplied by Mead Westvaco Corporation - MWV. Parameters were white liquor (WL): $88 \mathrm{~g} / \mathrm{L}$ effective alkali (EA) as $\mathrm{Na}_{2} \mathrm{O}$, green liquor (GL): $117 \mathrm{~g} / \mathrm{L}$ total titratable alkali (TTA) as $\mathrm{Na}_{2} \mathrm{O}$ and weak black liquor (BL): 15\% solids. These electrolytes, such as BL, were originated by southern hardwood mix and GL and WL were originated by Pine mix and hardwood mix.

\section{Results and Discussion}

\subsection{Microstructure Characterization}

Figure 1 shows typical microstructures found in asreceived duplex stainless (a) UNS 31803 steel cold rolled, (b) UNS 31803 steel hot rolled. Figure 2 shows (a) 2304 steel cold rolled and (b) 2304 steel hot rolled, respectively, containing only austenite (lighter) and ferrite phases (dark). Furthermore secondary phases, such as sigma and chi were not observed. The phases observed are elongated in the rolling direction as reported in literature ${ }^{21}$.
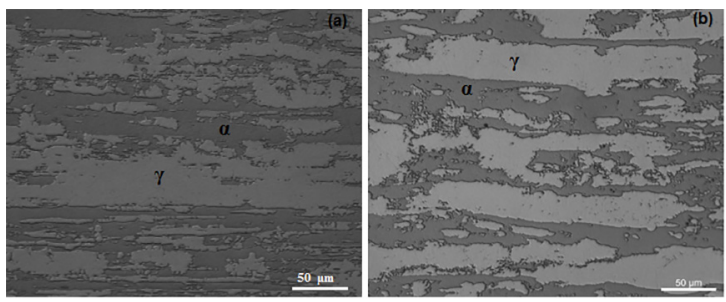

Figure 1: Typical microstructures found in the (a) UNS 31803 cold and (b) UNS 31803 hot rolling containing only austenite (clear) and ferrite (dark). Modified Behara Etching.
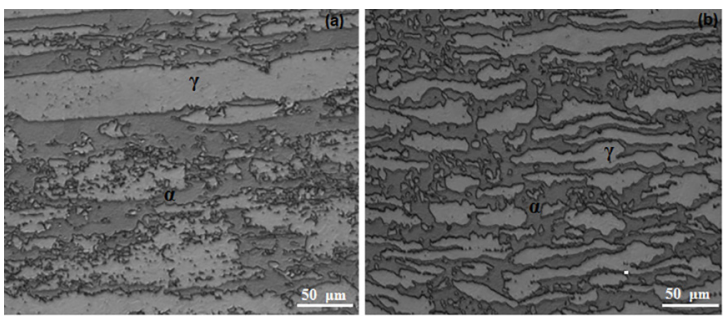

Figure 2: Typical microstructures found in the (a) 2304 cold and (d) 2304 hot rolling containing only austenite (clear) and ferrite (dark). Modified Behara Etching.

\subsection{Quantitative $X R D$ analysis}

Austenite and ferrite phases were identified in duplex and lean duplex steels, and secondary phases such as sigma $(\sigma)$ or chi $(\chi)$ phase were not observed in the steel microstructure. Visual evaluation of the graphic setting for both observed and calculated diffractograms is extremely important in assessing quality of refinement as shown in Figures 3 and 4. For refinement to be considered accurate, the line representing the calculated diffractogram should overlap the line that represents the observed diffractogram, and the difference line should be equal to a straight line ${ }^{22}$. Quality of the Rietveld refinement is verified through statistical numerical parameters (indicators) which are used during and after refinement in order to verify if it is occurring satisfactorily ${ }^{12}$. The most commonly used statistical parameters for the GSAS program are $\mathrm{R}_{\mathrm{p}}$ (profile factor), $\mathrm{R}_{\mathrm{wp}}$ (weighed profile factor), $\mathrm{R}_{\text {Bragg's }}$ (Bragg's index: this index compares the peaks' integrated intensities) and $\chi^{2}$ (Goodness of Fit $\left.=\mathrm{GOF}=\mathrm{S}\right)$.
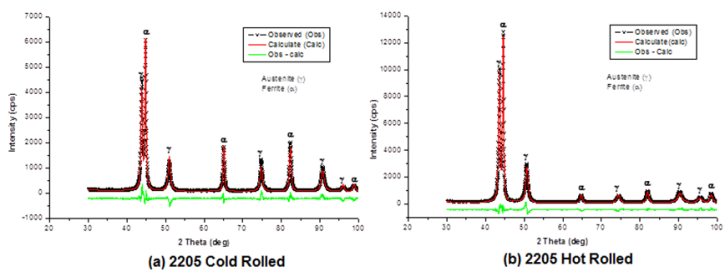

Figure 3: Observed (pluses) and calculated (line) diffraction pattern for the (a) UNS 31803 cold and (b) UNS 31803 hot rolling. The lower curve shows the difference between observed and calculated patterns.
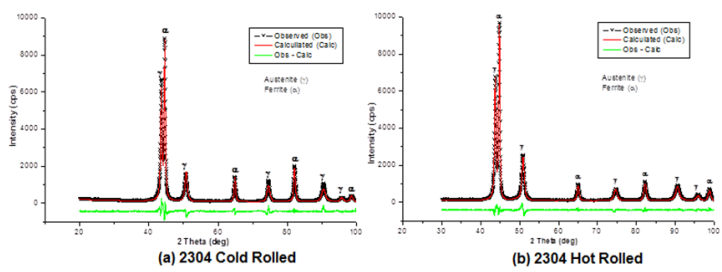

Figure 4: Observed (pluses) and calculated (line) diffraction pattern for the (a) 2304 cold and (b) 2304 hot rolling. The lower curve shows the difference between observed and calculated patterns.

The $\chi^{2}$ parameter values found for the UNS 31803 cold and hot rolled steels and the lean duplex cold and hot rolled steels were $3.5 \%, 3.4 \%, 3.6 \%$ and $2.4 \%$, respectively (Table 2). The $\chi^{2}$ parameter value should be equivalent to $1.0 \%$ in a perfect refinement. In practice, values below 5.0\% refer to an optimized refinement ${ }^{22}$. The $\mathrm{R}_{\text {Bragg's }}, \mathrm{R}_{\mathrm{p}}$ and $\mathrm{R}_{\mathrm{wp}}$ (Table 2) for the samples are somewhat higher than those normally obtained for refinement of simple phases ${ }^{12}$. This mismatch is due to the displacement of $2 \theta$ and peaks'symmetry ${ }^{23}$.

According to the XRD results shown in Table 2, the hot rolled steels exhibited a higher difference between the austenite and ferrite content. Consequently amounts of ferrite and austenite formed during hot working or annealing are dependent of temperature. Thus, hot working temperature must be controlled to obtain the balance between the phases in the duplex stainless steel ${ }^{24}$. The hot rolled duplex stainless steel showed a high content of austenite than the standard limit for duplex steels which can be associated with a limitation of Rietveld refinement, because this technique is usually applied for powder diffraction data ${ }^{23}$. Data collection might have promoted errors to justify the higher content of austenite than the standard limit of concentration. In the other hand, 
Table 2: Rietveld quantitative analysis results for DSSs samples.

\begin{tabular}{|c|c|c|c|c|c|c|}
\hline & \multicolumn{2}{|c|}{ Weight percent } & \multirow[b]{2}{*}{$\mathrm{R}_{\text {Braag }}$} & \multirow[b]{2}{*}{$\mathrm{R}_{\mathrm{wp}}$} & \multirow[b]{2}{*}{$\mathrm{R}_{\mathrm{p}}$} & \multirow[b]{2}{*}{$\chi^{2}$} \\
\hline & $\begin{array}{c}\text { Austenite } \\
(\gamma)\end{array}$ & $\begin{array}{l}\text { Ferrite } \\
(\alpha)\end{array}$ & & & & \\
\hline 31803 Cold & 49.9 & 50.1 & $5.9 \%$ & $8.7 \%$ & $8.7 \%$ & $3.5 \%$ \\
\hline 31803 Hot & 62.7 & 37.3 & $3.0 \%$ & $9.3 \%$ & $6.1 \%$ & $3.4 \%$ \\
\hline 32304 Cold & 54.3 & 45.7 & $4.0 \%$ & $10.7 \%$ & $8.2 \%$ & $3.6 \%$ \\
\hline 32304 Hot & 57.2 & 42.8 & $2.1 \%$ & $8.6 \%$ & $6.3 \%$ & $2.4 \%$ \\
\hline
\end{tabular}

Table 3 shows the contents of austenite and ferrite obtained using a conventional technique, the Image pro software by optical microscope. In summary the conventional method after etching with a modified Behara reagent was more reliable to quantify the content of austenite in duplex stainless steels. The main weakness of the Rietveld refinement is that it is usually performed for powder measurements and strengths of this technique are the lower time for analysis than the image analysis and the possibility of phase quantification if the lattice parameters are well defined and the diffraction peaks are not overlapping.

Table 3: Austenite and ferrite contents obtained using Image pro software.

\begin{tabular}{lcc}
\hline \multirow{2}{*}{ Samples } & \multicolumn{2}{c}{ Weight percent } \\
& Austenite $(\gamma)$ & Ferrite $(\mathrm{Fe}-\alpha)$ \\
\hline UNS 31803 Cold Rolled & 48 & 52 \\
UNS 31803 Hot Rolled & 50 & 50 \\
UNS 32304 Cold Rolled & 47 & 53 \\
UNS 32304 Hot Rolled & 46 & 54 \\
\hline
\end{tabular}

\subsection{Electrochemical Measurements}

Figures 5, 6 and 7 show the (a) Nyquist and (b) Bode diagrams of cold and hot rolled duplex stainless steels in white, green, and black liquors. Electrochemical impedance spectroscopy was used to evaluate the polarization resistance (Rp) of steels in liquors of pulp and paper industry. The EIS spectra were fitted using a simplified Randles circuit as an equivalent electrical circuit (EEC), which consisted of an electrolyte resistance ( $\mathrm{Re}$ ) in series with a parallel combination of a constant phase element and a polarization resistance as shown in Figure 8. Furthermore, Bode diagrams (Figures 5b, 6 b, and 7b) suggest the presence of one time constant. A second maximum identified in Bode curves of hot rolled UNS 31803 steel in white and green liquors occurred at higher frequencies above $10^{4} \mathrm{~Hz}$ and was not associated to a corrosive process. Constant phase elements (CPE) are used to describe the frequency dependence of non-ideal capacitive behavior (Table 4). The dimension of CPE is $\mathrm{s} / \Omega$, while that of an ideal capacitor (C) is $\mathrm{s} / \Omega$. When $\mathrm{n}$ is equal to 1 , a CPE simplifies to a capacitor; when $n$ equals 0 a CPE represents a pure resistor ${ }^{25}$. Low $\chi^{2}$ values were considered. The average of polarization resistance between the measurements in each solution is shown in Figure 9.
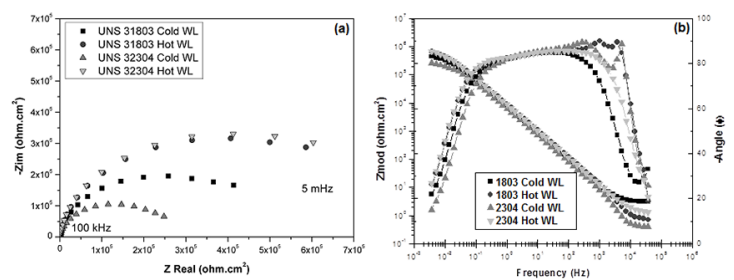

Figure 5: (a) Nyquist plot, (b) Bode plot of impedance spectra of UNS 31803 Cold, UNS 31803 Hot, 2304 Cold, and 2304 Hot rolling in white liquor.
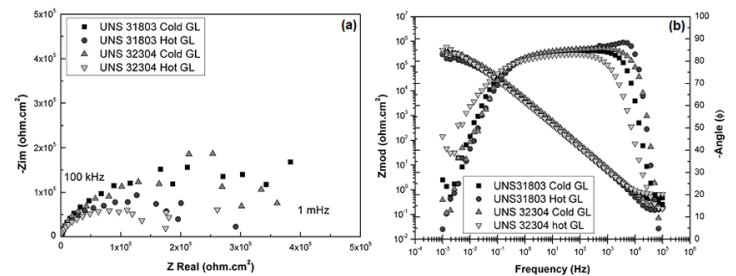

Figure 6: (a) Nyquist plot, (b) Bode plot of impedance spectra of UNS 31803 Cold, 1803 Hot, 2304 Cold, and 2304 Hot rolling in green liquor.
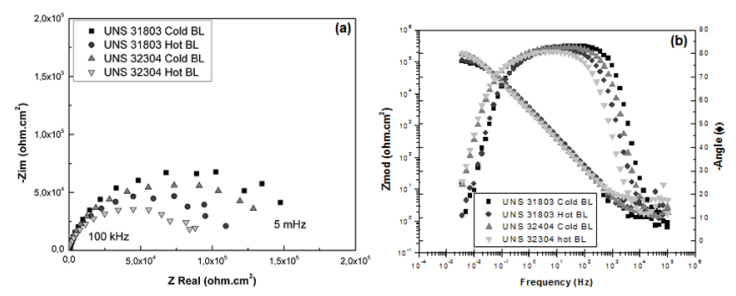

Figure 7: (a) Nyquist plot, (b) Bode plot of impedance spectra of UNS 31803 Cold, UNS 31803 Hot, 2304 Cold, and 2304 Hot rolling in black liquor.

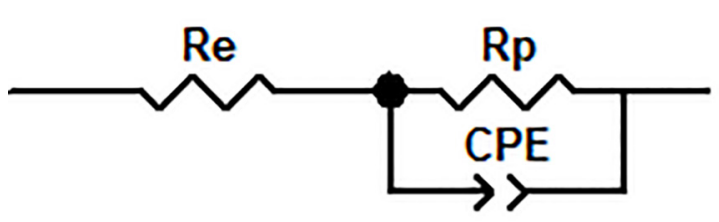

Figure 8: Electrical equivalent circuit (EEC) used for EIS experimental data fitting for the DSS 1803 and the DSS 2304 in pulp mill liquor. 


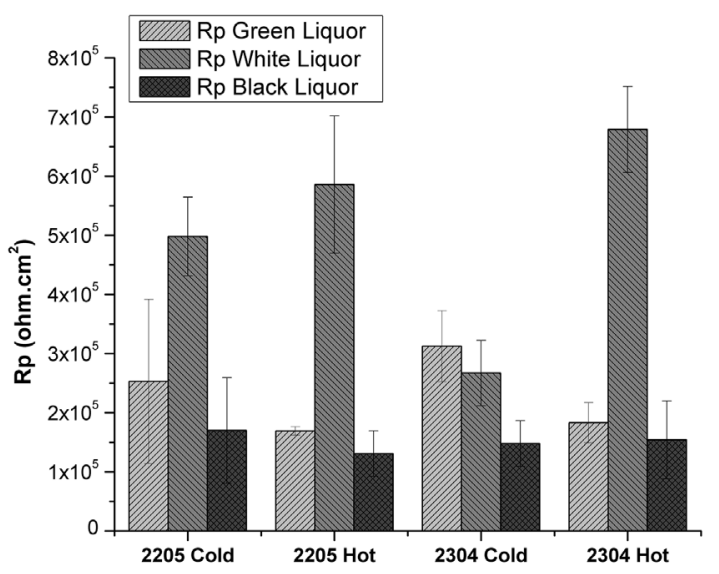

Figure 9: Experimental data for UNS 31803 Cold, UNS 31803 Hot, UNS 32304 Cold, UNS 32304 Hot in green liquor, white liquor, and black liquor.

Furthermore, the steels in black liquor showed a similar electrochemical behavior and exhibited the lowest polarization resistance compared to other environments. This effect could be associated to the presence of solid particles in black liquor which contains $15 \%$ of solids and, during the test, the solid particles can deposit on the steel surface generating regions of different potentials, and creating anodic and cathodic areas (and electrochemical cells). The deposition of solids on the steel surface should generate aeration cells where the region under the deposit is the anodic region (lower oxygen concentration). The solid particles deposited on the steel surface also can act as a cathodic region, reducing the active area and enhancing corrosion of steel. In addition, an industrial solution was used with a heterogeneous composition dependent of the type of wood and process conditions which contributes to the variability during the measurements. Literature reports that the organic compounds in black liquor can act as steel corrosion inhibitors ${ }^{16}$. However, in this work, in the black liquor, the steels showed the lowest values of corrosion potential and polarization resistance.

The medium of green liquor contains sodium sulfide and sodium carbonate which precipitated on the steel surface. The carbonate deposits generated aeration electrochemical cells and potential gradients on the steel surface. The surface area under the carbonate can act as an anodic region due to the lowest oxygen concentration. The carbonate precipitation can also reduce the anodic region on the steel surface and acts as a cathodic region where the cathodic reaction occurs. This condition contributes to enhance the corrosion of steels. The values of polarization resistance of steels in green liquor were similar, and higher than in black liquor but lower than in white liquor. In summary, particles in solution that allowed deposition on the surface of the working electrode showed more influence on the polarization resistance than microstructure of duplex.

The hot rolled steels showed a higher corrosion resistance in white liquor than the cold rolled steels. The cold rolled steel presented a more heterogeneous surface with elongated phases $^{26}$ (Figures 1 and 2), and a higher dislocation concentration generating several active sites to process corrosion. In white liquor, the standard duplex steels, which showed the highest PREN number and highest contents of nickel and molybdenum, showed a higher corrosion resistance than the lean duplex steels ${ }^{8}$ for cold working. However, the effect of molybdenum in caustic environments is not significant to improve corrosion resistance of duplex steels ${ }^{18}$. The hot rolling condition plays a major role in improving corrosion resistance in white liquor mainly for the lean duplex steel. The microstructure containing lower dislocation concentration contributes to enhance corrosion resistance of hot rolled steels in relation to the cold rolled condition.

The medium of white liquor was the less aggressive medium for both steels. In medium of white liquor, no precipitation of solids or compounds occurred on the steel surface. The white liquor contains sodium hydroxide, which

Table 4: Fitting results EIS Experimental Data in green liquor (GL), white liquor (WL), and black liquor (BL).

\begin{tabular}{lcccc}
\hline DSS & $\mathrm{OCP}\left(\mathrm{mV}_{\text {SCE }}\right)$ & $\mathrm{SD}\left(\mathrm{mV}_{\text {SCE }}\right)$ & $\mathrm{CPE}\left({\left.\mathrm{F} . \mathrm{s}^{\mathrm{n}} . \mathrm{cm}^{-2}\right)}^{\mathrm{n}}\right.$ \\
\hline 31803 Cold Rolled GL & -701.4 & 13.5 & $5.93 \times 10^{-5}$ & 0.93 \\
31803 Hot Rolled GL & -714.9 & 46.3 & $6.79 \times 10^{-5}$ & 0.91 \\
32304 Cold Rolled GL & -727.0 & 16.3 & $4.89 \times 10^{-5}$ & 0.93 \\
32304 Hot Rolled GL & -693.0 & 27.9 & $6.73 \times 10^{-5}$ & 0.92 \\
31803 Cold Rolled WL & -345.0 & 27.6 & $2.53 \times 10^{-5}$ & 0.95 \\
31803 Hot Rolled WL & -339.4 & 8.3 & $2.18 \times 10^{-5}$ & 0.95 \\
2304 Cold Rolled WL & -345.0 & 23.6 & $2.76 \times 10^{-5}$ & 0.95 \\
2304 Hot Rolled WL & -338.6 & 7.7 & $2.68 \times 10^{-5}$ & 0.94 \\
31803 Cold Rolled BL & -673.2 & 21.7 & $5.77 \times 10^{-5}$ & 0.93 \\
31803 Hot Rolled BL & -678.1 & 19.5 & $4.52 \times 10^{-5}$ & 0.90 \\
32304 Cold Rolled BL & -675.2 & 19.5 & $6.41 \times 10^{-5}$ & 0.92 \\
32304 Hot Rolled BL & -658.2 & 50.9 & $6.18 \times 10^{-5}$ & 0.91 \\
\hline
\end{tabular}


is beneficial to steel passivation, but contains sodium sulfide which is detrimental on the passivation behavior ${ }^{18}$.

\section{Conclusions}

Rietveld analysis was not efficient to determine the amount of austenite and ferrite in duplex and lean duplex steels and the influence of the rolling condition on the phase contents was identified.

The medium of white liquor was the less aggressive medium for both steels. The hot rolling condition plays a major role in improving corrosion resistance in white liquor mainly for the lean duplex steel.

The steels showed the lowest values of corrosion potential and polarization resistance in black liquor. Depositions of solids and carbonates on the steel surface in black and green liquors, respectively, contributed to reduce the corrosion resistance of duplex and lean duplex steels.

\section{Acknowledgements}

The authors are grateful to the Brazilian government agencies - CNPQ, CAPES and FAPEMIG.

\section{References}

1. Lai JKL, Shek CH, Lo KH. Stainless Steels: An Introduction and Their Recent Developments. Beijing: Bentham Science Publishers; 2012.

2. Itman Filho A, Silva RV, Cardoso WS, Casteletti LC. Effect of niobium in the phase transformation and corrosion resistance of one austenitic-ferritic stainless steel. Materials Research. 2014;17(4):801-806. doi: http://dx.doi.org/10.1590/15161439.190113

3. Michalska J, Sozańska M. Qualitative and quantitative analysis of $\sigma$ and $\chi$ phases in 2205 duplex stainless steel. Materials Characterization. 2006;56(4-5):355-362. doi:10.1016/j. matchar.2005.11.003.

4. Tan H, Jiang Y, Deng B, Sun T, Xu J, Li J. Effect of annealing temperature on the pitting corrosion resistance of super duplex stainless steel UNS S32750. Materials Characterization. 2009;60(9):1049-1054. doi:10.1016/j.matchar.2009.04.009.

5. Lo KH, Lai JKL, Shek CH, Li DJ. Effects of pre-treatment on the ac magnetic susceptibility and ageing behaviour of duplex stainless steels. Materials Science and Engineering: A. 2007;452-453:78-86. doi:10.1016/j.msea.2006.10.120.

6. Tavares SSM, Pardal JM, Silva MR, de Oliveira CAS. Martensitic transformation induced by cold deformation of lean duplex stainless steel UNS S32304. Materials Research. 2014;17(2):381-385.

7. Moura VS, Lima LD, Pardal JM, Kina AY, Corte RRA, Tavares SSM. Influence of microstructure on the corrosion resistance of the duplex stainless steel UNS S31803. Materials Characterization. 2008;59(8):1127-1132. doi:10.1016/j.matchar.2007.09.002.
8. Gunn RN. Duplex Stainless Steel: Microstructure, properties and applications. Cambridge: Abington Publishing, 1997.

9 Jones RH, ed. Environmental effects on engineered materials. New York: Marcel Dekker; 2001. doi:10.1201/9780203908129.

10. Garin JL, Mannheim RL. Rietveld Quantitative Analysis Of Super Duplex Stainless Steel. Advances in X Ray Analysis. 2012;55:98-105.

11. Rietveld HM. A profile refinement method for nuclear and magnetic structures. Journal of Applied Crystallography. 1969;2(Pt 2):65-71. doi:10.1107/S0021889869006558.

12. Young RA. The Rietveld Method. New York: Oxford University Press; 1995.

13. Bhattacharya A, Singh PM. Stress corrosion cracking of welded 2205 duplex stainless steel in sulfide-containing caustic solution. Journal of Failure Analysis and Prevention. 2007;7(5):371-377. doi:10.1007/s11668-007-9069-6.

14. Westin EM. Microstructure and properties of welds in the lean duplex stainless steel LDX 2101. [PhD Thesis]. Stockholm: Royal Institute of Technology; 2010.

15. Bajpai P. Biotechnology for Pulp and Paper Processing. New York: Springer; 2012. p. 7-15. doi:10.1007/978-1-4614-1409-4.

16. Singh PM, Anaya A. Effect of wood species on corrosion behavior of carbon steel and stainless steels in black liquors. Corrosion Science. 2007;49(2):497-509. doi:10.1016/j.corsci.2006.04.020.

17. Bajpai P. Chemical Recovery in Pulp and Papermaking. Surrey: Pira International; 2008.

18. Bhattacharya A, Singh PM. Electrochemical behaviour of duplex stainless steels in caustic environment. Corrosion Science. 2011;53(1):71-81. doi:10.1016/j.corsci.2010.09.024.

19. Magnabosco R. Kinetics of sigma phase formation in a Duplex Stainless Steel. Materials Research. 2009;12(3):321-327. http:// dx.doi.org/10.1590/S1516-14392009000300012

20. Toby BH. EXPGUI, a graphical user interface for GSAS. Journal of Applied Cristallography. 2001;34:210-213.

21. Revie RW, Uhlig HH. Corrosion and Corrosion Control: An introduction to corrosion science and engineering. $4^{\text {th }}$ ed. New Jersey: John Wiley \& Sons; 2008. doi:10.1179/000705972798323134.

22. Deysel K. Leucoxene Study - A Mineral Liberation Analysis (MLA) Investigation. In: Proceedings of the $6^{\text {th }}$ International Heavy Minerals Conference 'Back to Basics', The Southern African Institute of Mining and Metallurgy; 2007; Natal, South Africa. p. 167-172.

23. McCusker LB, von Dreele RB, Cox DE, Louër D, Scardi P. Rietveld refinement guidelines. Journal of Applied Crystallography. 2009;32(Pt 1):36-50. doi:10.1107/S0021889898009856.

24. Krauss G. Steel Processing, Structure, and Performance. $1^{\text {st }} \mathrm{ed}$. Materials Park: ASM International; 2005. doi:10.1038/129356a0.

25. Hsu CH, Mansfeld F. Technical Note: Concerning the Conversion of the Constant Phase Element Parameter $\mathrm{Y}_{0}$ into a Capacitance. Corrosion. 2001;57(9):747-748. doi:10.5006/1.3280607.

26. Jimenez JA, Carsi M, Ruano OA, Penãlba F. Characterization of a $\delta / \gamma$ duplex stainless steel. Journal of Materials Science. 2000;35(4):907-915. 